\title{
Mortality and chronic obstructive pulmonary disease in patients treated with endovascular revascularization of the infra-inguinal lower limb arteries from retrograde access
}

\author{
Zoltan Ruzsa ${ }^{1,2}$, Rafał Januszek ${ }^{3,4}$, Viktor Óriás ${ }^{1}$, Michał Chyrchel ${ }^{4}$, Joanna Wojtasik-Bakalarz ${ }^{4}$, \\ Jerzy Bartuś ${ }^{5}$, Saleh Arif ${ }^{4}$, Paweł Kleczyński ${ }^{4}$, Tomasz Tokarek ${ }^{4}$, Andras Nyerges ${ }^{2}$, Agata Stanek ${ }^{6}$, \\ Dariusz Dudek ${ }^{4,7}$, Stanisław Bartuś ${ }^{4,7}$
}

${ }^{1}$ Semmelweis University of Budapest, Cardiac and Vascular Center, Budapest, Hungary; ${ }^{2}$ Bács-Kiskun County Hospital, Invasive Cardiology Department, Teaching Hospital of the Szent-Györgyi Albert Medical University, Kecskemét, Hungary; ${ }^{3}$ University of Physical Education, Department of Clinical Rehabilitation, Kraków, Poland; ${ }^{4}$ 2nd Department of Cardiology and Cardiovascular Interventions, University Hospital, Krakow, Poland; J Jagiellonian University Medical College, Krakow, Poland; ${ }^{6}$ School of Medicine with the Division of Dentistry in Zabrze, Department of Internal Medicine, Angiology and Physical Medicine, Medical University of Silesia, Bytom, Poland; ${ }^{7} 2$ nd Department of Cardiology, Jagiellonian University Medical College, Krakow, Poland

Contributions: (I) Conception and design: S Bartuś, Z Ruzsa; (II) Administrative support: None; (III) Provision of study materials or patients: Z Ruzsa, S Bartuś, M Chyrchel, A Nyerges, V Óriás; (IV) Collection and assembly of data: S Bartuś, J Wojtasik-Bakalarz, A Stanek, Z Ruzsa, M Chyrchel; (V) Data analysis and interpretation: R Januszek, S Arif, J Bartuś, T Tokarek, D Dudek; (VI) Manuscript writing: All authors; (VII) Final approval of manuscript: All authors.

Correspondence to: Rafał Januszek, MD, PhD. 2nd Department of Cardiology and Cardiovascular Interventions, University Hospital in Krakow, ul. Kopernika 17, 31-501 Krakow, Poland. Email: jaanraf@interia.pl.

Background: In this trial, our objective was to evaluate the relationship between long-term clinical outcomes in patients with peripheral arterial disease (PAD) treated with retrograde endovascular recanalization (ER) of chronic total occlusions (CTOs) regarding the infra-inguinal lower limb arteries and chronic obstructive pulmonary disease (COPD).

Methods: A total of 834 consecutive subjects were enrolled in the study. The mean age was $67.8 \pm 10.6$ years (62.6\% males). COPD was diagnosed in 98 patients (11.7\%). The infra-inguinal location included the deep, superficial and common femoral artery, popliteal artery or below the knee arteries. During follow-up, we evaluated major adverse cardiac and cerebrovascular events (MACCE) and major adverse limb events (MALE). MACCE was considered as death, stroke/transient ischemic attack, myocardial infarction, percutaneous coronary intervention or coronary artery bypass grafting operation, while MALE regarded amputation, target lesion re-intervention, target vessel re-intervention and surgical action.

Results: The mean follow-up was $1,144.9 \pm 664.3$ days and the interquartile range was $1,110.5$ (504.51,734.7). Data were collected between 2006 and 2016. We noticed significant differences in death rates among the COPD and non-COPD groups. The cumulative number of events (deaths) was $12.2 \%, 17.3 \%$, $18.4 \%, 22.4 \%, 23.5 \%, 23.5 \%$ and $23.5 \%$ in the COPD group and $6.1 \%, 7.5 \%, 10.5 \%, 11.3 \%, 11.4 \% 11.5 \%$ and $11.5 \%$ in the non-COPD group after $1,2,3,4,5,6$ and 7 years of follow-up, and was notably greater for COPD ( $\mathrm{P}=0.0007)$.

Conclusions: Patients with COPD and PAD treated with the ER and retrograde approach due to CTOs are related to higher mortality than non-COPD patients.

Keywords: Lower limbs atherosclerosis; chronic total occlusions (CTO); retrograde access; clinical outcome; chronic obstructive pulmonary disease (COPD)

Submitted Aug 28, 2019. Accepted for publication Nov 11, 2019.

doi: $10.21037 /$ atm.2020.01.57

View this article at: http://dx.doi.org/10.21037/atm.2020.01.57 


\section{Introduction}

The endovascular revascularization (ER) procedures applied for patients with peripheral artery disease (PAD) are constantly improving and have become more attainable throughout the years. ER is the action of choice in the most cases experiencing symptomatic PAD. In the case of patients diagnosed with chronic total occlusion (CTO) of the lower limb arteries and failure of ER with antegrade access, retrograde access is an option for treatment prior to referral to a vascular surgeon or possible optimal medical therapy (OMT). In many research papers, the long-term results of regular ER with the use of antegrade access in PAD patients are presented. These publications include comparisons of antegrade and retrograde access sites $(1,2)$. Among predictors of clinical outcomes in these patients, the authors revealed such indices as c-reactive protein serum level, brain natriuretic peptide serum level, anemia, kidney failure, age, gender, diabetes or depression (3-9). Nonetheless, evaluation of predictors concerning long-term ER results among subjects experiencing PAD treated from retrograde access is less frequently described in the literature. This is mainly due to the low availability of large groups of subjects treated this way. This also applies to the consequences of chronic obstructive pulmonary disease (COPD) regarding ER results among the PAD group independently of vascular access. Data concerning those relationships are scarcely available in the literature. Studies on other groups of patients undergoing revascularization procedures including percutaneous interventions with atherosclerosis located in various vascular beds demonstrated statistically significantly higher adverse event rates for the COPD group in comparison with the non-COPD (10-13). COPD presence among PAD patients is itself associated with increased mortality (14). However, the group of patients with PAD and CTOs of the infra-inguinal arteries seems to be significantly different from those analyzed so far. CTOs of the infra-inguinal arteries are often associated with chronic and critical muscle ischemia of below-the-knee parts of muscle groups larger than average. Those patients are more often prone to necrotizing pro-inflammatory lesions. It can, therefore, be assumed that the increase of pro-inflammatory markers and other toxic substances for the body in blood exceeds the negative effect of COPD on the results of endovascular treatment in this group of patients during long-term follow-up. We wanted to estimate with which of the individual MACCE and MALE components the coexistence of COPD has the greatest relationship.

Consequently, the objective of this study is assessment of the correlation for COPD and long-term clinical outcomes regarding ER of CTOs from retrograde entrée among PAD subjects, with special insight into survival analysis.

\section{Methods}

\section{Study population}

This research project was organized as a prospective observational study of consecutive patients undergoing retrograde recanalization of $\mathrm{CTO}$ in the superficial femoral artery (SFA), popliteal artery (PA) or belowthe-knee arteries. At two experienced and collaborating centres, all consecutive patients were enrolled following a minimum of one ineffective antegrade recanalization of CTO eligible for the retrograde access method. Inability to perform antegrade was considered failure to wire the distal part of the vessel following occlusion via access site, found in the contralateral artery or proximal to the CTO lesion. The inability to wire the distal part of the CTO was caused by failure to penetrate the lesion or because of failure to return to the arterial lumen after subintimal recanalization in given cases with suitable anatomy and morphology of target lesions. Crossing devices and/or micro wires facilitating intraluminal penetration of CTOs were applied to a limited extent because of a notable rise the treatment expenses. Nonetheless, this had no influence on the results of statistical calculations. Consistent with the applicable modus operandi, patients underwent screening for concomitant illnesses, risk factors and medication before the treatment. Ankle-brachial index was examined and PAD severity was evaluated on the basis of the Rutherford and/or Fontaine scales for all participants prior to the procedure. The choice considering retrograde recanalization and access site was based on earlier performed angiography. The retrograde recanalization action was conducted under local anesthesia and demanded two access sites: antegrade and retrograde. Both proximal and distal punctures were conducted under the guidance of vascular ultrasound and/ or fluoroscopy. The choice of antegrade access site was influenced by various factors, among others, anatomical conditioning, type of vascular lesions (dissemination, calcifications, length), technical potential (having sufficiently long catheters), type of occlusions, its length and likelihood of blood flow restoration. In the case of the proximal access site, the contralateral femoral artery was utilised most frequently, and $6 \mathrm{Fr}$ vascular sheaths were some of the most popular. The distal access site was typically selected for the artery's reconnection area 
(needle: $12-15 \mathrm{~mm}, 21 \mathrm{G})$. In some situations, 4 Fr vascular sheaths were required to acquire support at the time of the procedure. In a couple of instances, the distal access site was additionally applied in the case of revascularization of the more peripheral artery fragments. The hydrophilic $0.035^{\prime \prime}(0.89 \mathrm{~mm})$ guidewire was implemented for the antegrade access site. Occlusions were crossed from the retrograde access site using non-hydrophilic 0.018" $(0.46 \mathrm{~mm})$ guidewires. After crossing the occlusion with a wire using the retrograde approach, we carried out pre-dilatation via a balloon catheter. Then, the operator decided whether or not to implant the stent. Following the procedure, the distal sheet was instantaneously taken out, while the proximal one was in place for a maximum of 4 hours until puncturing of the femoral artery took place. This was modified via the usage of unfractionated heparin. Because of dissection, in a few instances, the inflation of the balloon was conducted from ante- and retrograde access (which is the kissing balloon technique) in order to tear the dissection and to facilitate capturing the wire via the diagnostic catheter. The first antegrade puncture site was used to visualize the vessel at the time of the retrograde access procedure, antegrade puncture site one was utilized for vessel visualization. This was distinguished as the first access site for angiography. In a number of the patients, because of anatomically-, morphologically- or technicallyrelated issues, it was impossible to access the artery's distal part being treated via retrograde access for angiography. These patients were forced to undergo puncturing of a different artery-considered the second, third or fourth antegrade site for angiography access. For periprocedural management, all patients underwent double antiplatelet treatment: aspirin $75 \mathrm{mg}$ - permanently, and clopidogrel $75 \mathrm{mg}$ for a 3-month period, high level dosages of statin and, in accordance with the applicable practice, low-molecularweight heparin for a 4-week period. Supplementary treatment was in applied according to individual risk factors as well as deaths. COPD was defined according to the current international guidelines by the presence of irreversible airflow obstruction [post-bronchodilator first second expiratory volume $\left(\mathrm{FEV}_{1}\right)$ /forced vital capacity (FVC) $<0.70]$ and corrected according to age-related cut-off values not higher than the lower fifth percentile [lower limit of normal] of this quotient taken from the general population) and was confirmed by the treating specialist of respiratory diseases. This was verified by spirometry in each case (10). In

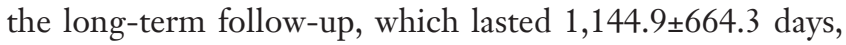
the patients underwent evaluation regarding major adverse cardiac as well as cerebrovascular events (MACCE), major adverse limb events (MALE). The data were accumulated during the 2006-2016 period. In the case of this study, MACCE were pre-established as comorbidity, stroke/TIA, myocardial infarction, percutaneous coronary intervention (PCI) or coronary artery bypass grafting (CABG). MALE was considered as amputation, target vessel re-intervention, target lesion re-intervention as well as surgical treatments. Because of deficiencies in accessible sources, the amputation level was not emphasized in this work, and alike high-, mid- and low-amputations, they were part of the concept regarding the total rate of amputations. The protocol was in accordance with the 1964 Declaration of Helsinki, and all of the participants gave their informed and written consent to take part in the trial. Due to the fact that the data in the study were collected retrospectively, the consent of the Bioethics Committee was not required.

\section{Statistical analysis}

Categorical variables are demonstrated as numbers and proportions, while the continuous ones are presented as means (standard deviation, SD) or median as well as interquartile range. The variable characterization was determined via normality with the Shapiro-Wilk test. Variance equality was analyzed via the test by Levene's. Inter-group disripancies were subjected to comparison the Student's or Welch's $t$-tests, which was dependent on variance equality for those variables that were characterized by normal distribution. The Mann-Whitney U-test was applied for continuous variables characterized by nonnormal distribution. Comparison of categorical variables was done with the chi-squared test by Pearson or using Fisher's exact test when $20 \%$ of the cells had the anticipated count below five. The Cochrane-Armitage trend test was applied to compare the ordinal variables. For analysis of survival-rate among selected groups under risk, we performed computations of Kaplan-Meier curves. The logrank statistic test was implemented to determine differences in the results for particular groups. All of the performed statistical analyses were conducted via JMP ${ }^{\circledR}$, Version 13.1.0 (SAS Institute INC., Cary, NC, USA). A P value below 0.05 was considered to be of statistical significance. The size of the sample was not counted because the reported work was based on the database registry, the original purpose of which was not to assess the impact of COPD on mortality. All analyzes were calculated lesion-based. In the case of bilateral involvement, one limb was included in the analysis 
Table 1 General characteristics, clinical presentation and biochemical indices

\begin{tabular}{|c|c|c|c|}
\hline Variables & $\begin{array}{c}\text { Non-COPD } \\
(n=736)\end{array}$ & $\begin{array}{l}\text { COPD } \\
(n=98)\end{array}$ & $P$ value \\
\hline Age, years & $68.1 \pm 10.7$ & $68.6 \pm 11.2$ & $0.6^{u}$ \\
\hline Male gender, \% & 58.3 & 78.6 & $<0.001^{P}$ \\
\hline Body mass index, $\mathrm{kg} / \mathrm{m}^{2}$ & $27.4 \pm 5.4$ & $26.2 \pm 5.5$ & $0.2^{u}$ \\
\hline Hypertension, \% & 88.8 & 88.8 & $0.98^{P}$ \\
\hline Diabetes, \% & 52.8 & 37.8 & $0.005^{P}$ \\
\hline Renal failure, \% & 16.0 & 17.3 & $0.74^{P}$ \\
\hline Coronary artery disease, $\%$ & 32.3 & 49.0 & $0.001^{P}$ \\
\hline $\begin{array}{l}\text { Stroke/transient ischemic } \\
\text { attack, \% }\end{array}$ & 8.7 & 7.1 & $0.6^{P}$ \\
\hline Smoking, \% & 59.4 & 75.8 & $0.07^{\mathrm{P}}$ \\
\hline Prior PTA, \% & 19.0 & 32.0 & $0.001^{P}$ \\
\hline Prior bypass surgery, $\%$ & 9.7 & 18.4 & $0.008^{P}$ \\
\hline \multicolumn{4}{|l|}{ Biochemical indices } \\
\hline Hemoglobin, g/dL & $13.6 \pm 1.6$ & $14.2 \pm 1.3$ & $0.45^{\mathrm{s}}$ \\
\hline Platelet count, $\times 1,000 / \mu \mathrm{L}$ & $240.9 \pm 69.1$ & $218.7 \pm 71.6$ & $0.59^{s}$ \\
\hline Creatinine, $\mu \mathrm{mol} / \mathrm{L}$ & $88.4 \pm 47.6$ & $81 \pm 12.2$ & $0.65^{\mathrm{U}}$ \\
\hline eGFR, mL/min/1.73 m² & $54.8 \pm 11.8$ & $60 \pm 12.4$ & $0.26^{U}$ \\
\hline \multicolumn{4}{|c|}{ Clinical presentation before angioplasty } \\
\hline $\begin{array}{l}\text { Rutherford classification } \\
\text { (15), \% }\end{array}$ & & & $0.87^{\mathrm{CA}}$ \\
\hline 0 & 0 & 0 & \\
\hline 1 & 2.6 & 4.3 & \\
\hline 2 & 16.1 & 13.0 & \\
\hline 3 & 13.9 & 9.8 & \\
\hline 4 & 17.9 & 26.1 & \\
\hline 5 & 16.5 & 13.0 & \\
\hline 6 & 33.0 & 33.8 & \\
\hline Fontaine scale (16), \% & & & $0.82^{\mathrm{CA}}$ \\
\hline $2 a$ & 2.7 & 4.3 & \\
\hline $2 b$ & 31.2 & 22.8 & \\
\hline 3 & 16.8 & 26.1 & \\
\hline 4 & 49.3 & 46.8 & \\
\hline
\end{tabular}

Table 1 (continued)
Table 1 (continued)

\begin{tabular}{lccc}
\hline Variables & $\begin{array}{c}\text { Non-COPD } \\
(\mathrm{n}=736)\end{array}$ & $\begin{array}{c}\text { COPD } \\
(\mathrm{n}=98)\end{array}$ & P value \\
\hline Wagner scale (17), \% & & & $0.23^{\mathrm{CA}}$ \\
0 & 4.6 & 0 & \\
1 & 13.7 & 12.5 & \\
2 & 8.8 & 4.2 & \\
3 & 0.4 & 0 & \\
4 & 67.1 & 75.0 & \\
5 & 5.4 & 8.3 \\
\hline
\end{tabular}

CA, Cochran-Armitage test for trend; eGFR, estimated glomerular filtration rate; ${ }^{\text {, }}$ Pearson's chi-squared test; PTA, percutaneous transluminal angioplasty; ${ }^{\text {s }}$, Student's $t$-test; ' , Mann-Whitney $U$ test; COPD, chronic obstructive pulmonary disease.

and this was recognized as one ER, which in some cases, could be multi-segmental. The treated lesion concerned the limb which was clinically more affected by ischemia.

\section{Patient participation}

None of the studied patients had any direct involvement in posing the research questions, the choice of the outcome means, the research plan, its execution, or in result interpretation.

\section{Results}

\section{General description}

In total, the study comprised 834 patients. There were 736 participants $(58.3 \%$ males $)$ in the non-COPD group and 98 subjects $(78.6 \%$ males) within the COPD group. The mean age did not differ significantly between both investigated groups $68.1 \pm 10.7$ and $68.6 \pm 11.2$ years, respectively $(\mathrm{P}=0.6)$. Diabetes occurred more often in the non-COPD group compared to COPD (52.8\% vs. $37.8 \%$; $\mathrm{P}=0.005)$, while concomitant coronary artery disease $(49.0 \%$ vs. $32.3 \% ; \mathrm{P}=0.001)$, prior percutaneous transluminal angioplasty (PTA) $(32.0 \%$ vs. $19.0 \% ; \mathrm{P}=0.001)$ and the bypass surgical procedure $(18.4 \%$ vs. $9.7 \% ; \mathrm{P}=0.008)$ occurred significantly more often in the COPD group. In the comparison of the COPD and non-COPD groups, the 
difference in the percentage of smokers was not statistically significant $(59.4 \%$ vs. $75.8 \% ; \mathrm{P}=0.07)$. There were no statistically significant differences between the mean serum creatinine $(88.4 \pm 47.6$ vs. $81 \pm 12.2 \mu \mathrm{mol} / \mathrm{L} ; \mathrm{P}=0.65)$ and hemoglobin $(13.6 \pm 1.6$ vs. $14.2 \pm 1.3 \mathrm{mg} / \mathrm{dL}, \mathrm{P}=0.45)$ levels. Those and other indices are presented in Table 1.

\section{Clinical presentation}

Acute limb ischemia was an indication for angioplasty more often in the COPD group $(8.16 \%$ vs. $5.16 \% ; \mathrm{P}=0.22)$. Patients with acute ischemia constituted a significant minority of the whole and were mostly patients with chronic critical limb ischemia that had deteriorated. Patients were qualified for ER mainly due to their willingness to avoid surgical treatment and the potential for the successful endovascular procedure based on angiographic examination. Also, critical limb ischemia was more often an indication for angioplasty in the COPD group compared to nonCOPD (68.4\% vs. $62.1 \% ; \mathrm{P}=0.22)$. While intermittent claudication was an indication for angioplasty more often in the non-COPD in comparison to the COPD group (32.6\% vs. $24.5 \% ; \mathrm{P}=0.1)$. Other clinical scales illustrating clinical symptoms of PAD like Fontaine's scale, the Rutherford classification and Wagner scale can be seen in Table 1.

\section{Indicators of angiography and the procedure}

In accordance with the classification proposed by the Trans-Atlantic Inter Society Consensus (TASC II), more disseminated atherosclerotic lesions were observed in the COPD in contrast to non-COPD $(\mathrm{P}=0.02)$. The concomitant significant stenosis of the iliac artery $(20.4 \%$ vs. $11.5 \% ; \mathrm{P}=0.01)$ and the common femoral artery (CFA) $(7.5 \%$ vs. $3.5 \% ; \mathrm{P}=0.16)$ before PTA was noticed more frequently for the COPD with regard to nonCOPD. Additionally, the average lesion length in the CFA (13.4 \pm 14.6 vs. $18.5 \pm 21.9 \mathrm{~mm} ; \mathrm{P}=0.1)$, SFA $(124.5 \pm 108.9$ vs. $152.5 \pm 118.3 \mathrm{~mm} ; \mathrm{P}=0.02)$ and $\mathrm{PA}(51.9 \pm 48.5$ vs. $55.4 \pm 49.6 \mathrm{~mm} ; \mathrm{P}=0.56)$ was longer in the COPD. The procedural success expressed as residual stenosis $<40 \%$ estimated by angiography was achieved in $90.2 \%$ of patients from the COPD group, and for $86.7 \%$ of the subjects in the non-COPD $(\mathrm{P}=0.29)$. In contrast, procedure-related accomplishment presented as residual stenosis $<30 \%$ was attained in $89.5 \%$ of subjects in the COPD and $83.7 \%$ of patients from the non-COPD $(\mathrm{P}=0.08)$. The total count of complications during the procedure was notably higher in the non-COPD group when weighed against the COPD ( $6 \%$ vs. $1 \% ; \mathrm{P}=0.04$ ), the rate of major vascular complications was not statistically significantly higher in the COPD group compared to non-COPD ( $7.1 \%$ vs. $3.3 \%$; $\mathrm{P}=0.08)$. Major vascular complications included, inter alia, the need for surgical intervention due to artery dissection and transfusion of blood substitutes. Intraprocedural complications covered, among others, allergic reactions or contrast-induced nephropathy. Minor vascular complications, which included mostly local bleeding treatable with local compression, occurred more often in the non-COPD vs. COPD group ( $13.5 \%$ vs. $9.2 \%, \mathrm{P}=0.23$ ). We noted only some cases of complications related to retrograde access, and they were mild bleeding complications from the puncture site or small hematomas. We did not notice arterio-venous fistulas as a complication of the retrograde access site. Hospitalization duration was considerably lengthier in the COPD compared to the non-COPD $(7.44 \pm 7.44$ vs. $5.22 \pm 4.95$ days; $\mathrm{P}=0.008)$. Those and other angiographic and procedural indices are presented in Table 2.

\section{Short-term results}

The total number of deaths within 30 days post-procedure totaled $3.06 \%$ in the COPD group and was $2.04 \%$ for the non-COPD group $(\mathrm{P}=0.5)$. Whereas the cumulative number of amputations within 30 days of follow-up was $10.7 \%$ for the COPD and $8.7 \%$ in the case of non-COPD $(\mathrm{P}=0.5)$.

\section{Clinical endpoint}

The follow-up lasted 84 months. During this time, endovascular re-interventions in lower limb arteries occurred not statistically significantly more often in the nonCOPD compared to the COPD group (36\% vs. $27.5 \%$; $\mathrm{P}=0.09)$. While the rates of myocardial infarctions $(5.1 \%$ vs. $2.9 \% ; \mathrm{P}=0.21)$, amputations $(22.3 \%$ vs. $18.4 \% ; \mathrm{P}=0.35)$ and lower-limb bypass surgery (6.4\% vs. $4.9 \% ; \mathrm{P}=0.61)$ were not viewed as having more statistical significance in the COPD versus non-COPD group. The only significant difference between both investigated groups was noticed for death rate, which was more than two times greater for the COPD in relation to the non-COPD ( $23.5 \%$ vs. $11.5 \% ; \mathrm{P}=0.001)$. The log-rank test confirmed statistically significant differences between those two groups ( $\mathrm{P}=0.0007)$. This is presented in Figure 1 and Tables 3,4. In Table 5, the outcome of univariate Cox analysis can be found. Furthermore, multivariate 
Table 2 Culprit artery, lesion and procedural indices

\begin{tabular}{|c|c|c|c|}
\hline Selected indices & Non-COPD & COPD & $P$ value \\
\hline TASC II (18), \% & & & $0.02^{\mathrm{CA}}$ \\
\hline A & 19.7 & 17 & \\
\hline B & 21.3 & 11 & \\
\hline $\mathrm{C}$ & 15.7 & 11 & \\
\hline $\mathrm{D}$ & 43.3 & 61 & \\
\hline $\begin{array}{l}\text { Angiography - first access } \\
\text { site, \% }\end{array}$ & & & $0.01^{P}$ \\
\hline Brachial & 3 & 8.2 & \\
\hline Femoral & 73 & 62.9 & \\
\hline Radial & 24 & 28.9 & \\
\hline $\begin{array}{l}\text { Angiography - number of } \\
\text { access sites, } \%\end{array}$ & & & $0.21^{\mathrm{CA}}$ \\
\hline 1 & 82.3 & 76.5 & \\
\hline 2 & 16.2 & 21.4 & \\
\hline 3 & 1.2 & 2.1 & \\
\hline 4 & 0.3 & 0 & \\
\hline $\begin{array}{l}\text { Angiography-first access } \\
\text { side, } \%\end{array}$ & 65.2 & 72.4 & $0.15^{\mathrm{P}}$ \\
\hline \multicolumn{4}{|l|}{ Right } \\
\hline Left & 34.8 & 27.6 & \\
\hline $\begin{array}{l}\text { Iliac artery-significant } \\
\text { lesion, \% }\end{array}$ & 11.5 & 20.4 & $0.01^{P}$ \\
\hline $\begin{array}{l}\text { Deep femoral artery- } \\
\text { significant lesion, \% }\end{array}$ & 4.8 & 6.1 & $0.61^{F}$ \\
\hline \multicolumn{4}{|l|}{ Common femoral artery } \\
\hline Tortuosity & & & $0.22^{F}$ \\
\hline Slight & 5.6 & 1.5 & \\
\hline No & 94.4 & 98.5 & \\
\hline Chronic total occlusion & 3.5 & 7.5 & $0.16^{F}$ \\
\hline Calcification & & & $0.93^{\mathrm{CA}}$ \\
\hline No & 46.4 & 46.3 & \\
\hline Slight & 37.8 & 38.8 & \\
\hline Severe & 15.8 & 14.9 & \\
\hline Lesion length, $\mathrm{mm}$ & $13.4 \pm 14.6$ & $18.5 \pm 21.9$ & $0.1^{\mathrm{U}}$ \\
\hline
\end{tabular}

Table 2 (continued)
Table 2 (continued)

\begin{tabular}{|c|c|c|c|}
\hline Selected indices & Non-COPD & COPD & $P$ value \\
\hline \multicolumn{4}{|l|}{ Superficial femoral artery } \\
\hline Tortuosity & & & $0.54^{\mathrm{CA}}$ \\
\hline Severe & 2.5 & 4.3 & \\
\hline Slight & 35.1 & 28 & \\
\hline No & 62.4 & 67.7 & \\
\hline Chronic total occlusion & 49.9 & 48.4 & $0.78^{P}$ \\
\hline Calcification & & & $0.67^{\mathrm{CA}}$ \\
\hline Extreme & 3.3 & 2.1 & \\
\hline Severe & 43.8 & 41.9 & \\
\hline Slight & 35.3 & 38.7 & \\
\hline No & 17.6 & 17.3 & \\
\hline Lesion length, $\mathrm{mm}$ & $124.5 \pm 108.9$ & $152.5 \pm 118.3$ & $0.02^{U}$ \\
\hline $\begin{array}{l}\text { Popliteal artery-lesion } \\
\text { length, } \mathrm{mm}\end{array}$ & $51.9 \pm 48.5$ & $55.4 \pm 49.6$ & $0.56^{U}$ \\
\hline \multicolumn{4}{|l|}{$\begin{array}{l}\text { Lesion location in crural } \\
\text { arteries, } \%\end{array}$} \\
\hline Tibio-fibular trunk & 24.1 & 29.6 & $0.23^{P}$ \\
\hline Tibialis anterior artery & 46 & 50 & $0.45^{\mathrm{P}}$ \\
\hline Peroneal artery & 35.8 & 42.3 & $0.21^{P}$ \\
\hline Tibialis posterior artery & 47.4 & 48 & $0.91^{\mathrm{P}}$ \\
\hline Fluoroscopy time, s & $846.6 \pm 712.6$ & $682.4 \pm 578.2$ & $0.25^{u}$ \\
\hline Contrast volume, $\mathrm{mL}$ & $119 \pm 83.6$ & $134.6 \pm 90.5$ & $0.11^{u}$ \\
\hline $\begin{array}{l}\text { Time from procedure to } \\
\text { discharge, days }\end{array}$ & $3.63 \pm 2.31$ & $2.25 \pm 0.5$ & $0.33^{\mathrm{U}}$ \\
\hline Hospitalization time, days & $5.22 \pm 4.95$ & $7.44 \pm 7.44$ & $0.008^{U}$ \\
\hline $\begin{array}{l}\text { Intraprocedural } \\
\text { complications, \% }\end{array}$ & 6 & 1 & $0.04^{P}$ \\
\hline $\begin{array}{l}\text { Major vascular } \\
\text { complications, \% }\end{array}$ & 3.3 & 7.1 & $0.08^{F}$ \\
\hline $\begin{array}{l}\text { Minor vascular } \\
\text { complications, \% }\end{array}$ & 13.5 & 9.2 & $0.23^{P}$ \\
\hline
\end{tabular}




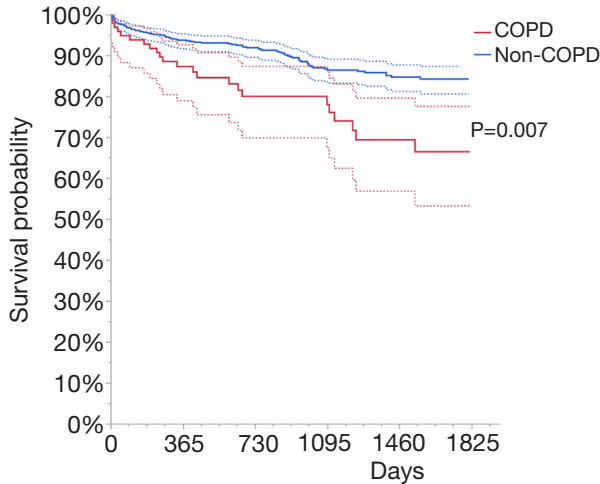

Figure 1 The Kaplan-Meier curve for survival analysis regarding the COPD grouping variable. COPD, chronic obstructive pulmonary disease.
Cox analysis established a correlation of significance among COPD and death rate: hazard ratio (HR) and $95 \%$ confidence interval (CI) was 2.17 (1.34-3.38), $\mathrm{P}=0.0023$.

The overall study endpoints including MACCE and MALE did not differ significantly between COPD and non-COPD group (RR: 1.1, 95\% CI: 0.84-1.46, $\mathrm{P}=0.45$ ) during the follow-up stage. There were also no significant relationships for MALE (RR: 0.9, 95\% CI: 0.66-1.24, $\mathrm{P}=0.54)$. However, there were significantly higher rates of MACCE in the COPD group compared to the non-COPD group (RR: 1.98, 95\% CI: 1.3-3.02, $\mathrm{P}=0.0014$ ). This was mostly caused by greater myocardial infarction, cerebral stroke/transient ischemic attack and death rates. Of these, mortality was the major difference.

Table 3 The frequency of study endpoints and duration of follow-up according to the COPD status

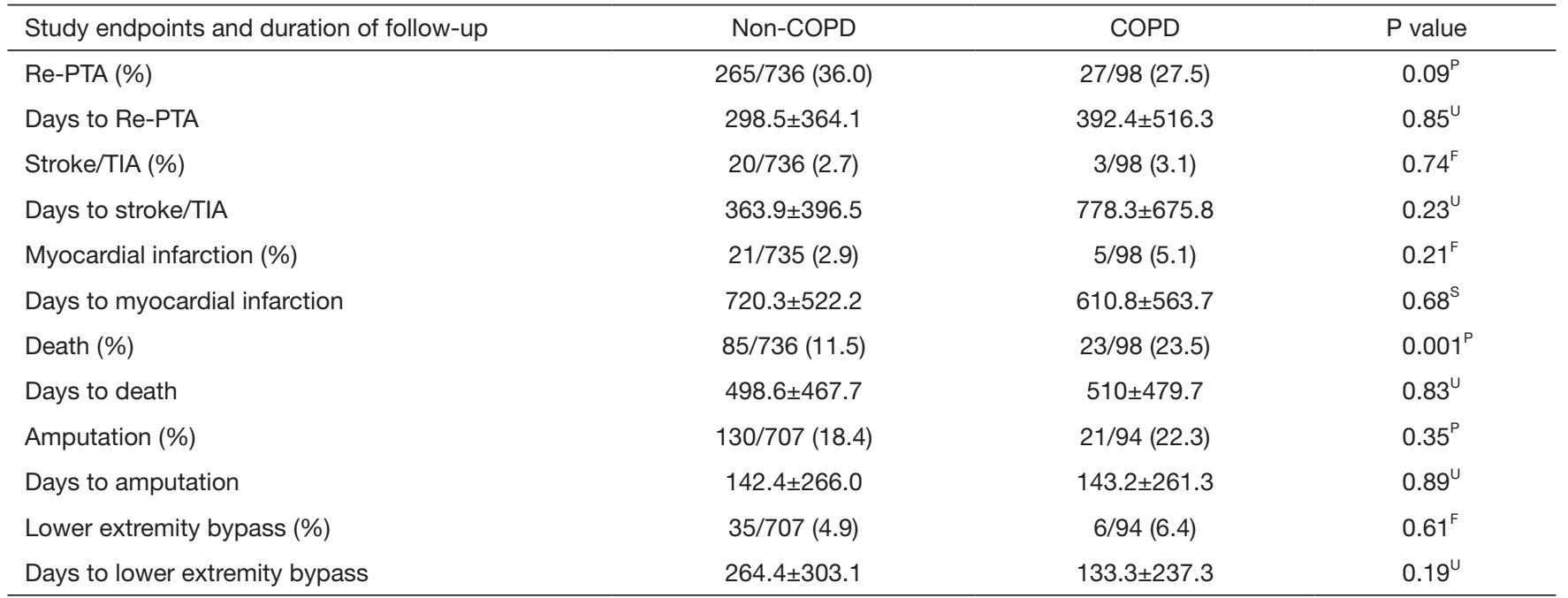

F, Fisher's exact test; ${ }^{\text {, }}$ Pearson's chi-squared test; PTA, percutaneous transluminal angioplasty; ${ }^{\text {' }}$, Student's $t$-test; TIA, transient ischemic attacks; ' , Mann-Whitney $U$ test; COPD, chronic obstructive pulmonary disease.

Table 4 Cumulative risk of death according to COPD status $(\mathrm{P}=0.0007)$

\begin{tabular}{|c|c|c|c|c|c|c|c|c|}
\hline COPD & 0 months & 12 months & 24 months & 36 months & 48 months & 60 months & 72 months & 84 months \\
\hline At risk & 98 & 69 & 51 & 40 & 26 & 16 & 8 & 1 \\
\hline Cumulative number of events & 0 & 12 & 17 & 18 & 22 & 23 & 23 & 23 \\
\hline \multicolumn{9}{|l|}{ No } \\
\hline At risk & 736 & 588 & 448 & 316 & 216 & 128 & 32 & 3 \\
\hline \multicolumn{9}{|l|}{ Total } \\
\hline At risk & 834 & 657 & 499 & 356 & 242 & 144 & 40 & 4 \\
\hline Cumulative number of events & 0 & 57 & 72 & 95 & 105 & 107 & 108 & 108 \\
\hline
\end{tabular}

COPD, chronic obstructive pulmonary disease. 
Table 5 The univariate Cox model for death depending on COPD

\begin{tabular}{lcl}
\hline Outcome & $\mathrm{HR}(95 \% \mathrm{Cl})$ & $\mathrm{P}$ value \\
\hline Death & $2.17(1.34-3.38)$ & 0.86 \\
Stroke/TIA & $1.11(0.26-3.24)$ & 0.002 \\
Myocardial infarction & $1.89(0.63-4.68)$ & 0.23 \\
Re-PTA & $0.73(0.48-1.07)$ & 0.11 \\
Lower extremity bypass & $1.30(0.54-3.10)$ & 0.54 \\
Amputation & $1.23(0.74-1.92)$ & 0.41 \\
PTE/TEA & $1.07(0.06-6.03)$ & 0.94 \\
\hline
\end{tabular}

$\mathrm{Cl}$, confidence interval; HR, hazard ratio; PTA, percutaneous transluminal angioplasty; PTE, percutaneous thrombectomy; TEA, thromboendarterectomy; TIA, transient ischemic attack; COPD, chronic obstructive pulmonary disease.

\section{Discussion}

The key result of this study shows that PAD patients and those with diagnosed COPD prior to endovascular CTO treatment of the lower extremity infra-inguinal arteries are at a higher risk of death at the time of the long-term follow-up phase compared to the group of non-COPD patients. Numerous accessible research papers have shown MACCE and MAPE predictors during the follow-up in PAD patients treated with endovascular interventions. Since the first publication concerning the results of percutaneous angioplasty in PAD patients from a retrograde approach, the results of treatment have significantly improved (19). Nevertheless, there is still a lack of research among large populations approximating predictors of long-term management outcomes among this particular patient group, above all, in the case of subjects undergoing retrograde approach treatment. In this study, the death rate after 7 years of follow-up totaled $23.5 \%$ in the COPD group and $4.3 \%$ in among the non-COPD group, which was comparatively low in contrast to different and older papers in which the death rate for total group of PAD patients subjected to endovascular interventions amounted to $4.3-50 \%$ - comparable baseline mean age of the subjects participating in this trial, and dependent on follow-up duration (20-22). In their analysis, Bertelè et al. studied 1,560 patients at the mean age of 70.8 (10.1) years with chronic/critical limb ischemia treated with different methods of revascularization. They reported mortality rates of $13.4 \%$ after 6 months and $19.1 \%$ after 12 months. Greater mortality was related to older age, prior stroke, myocardial infarction and diabetes while prior revascularizations were related to lower death rate but higher amputation rate (20). Löfberg et al. presented a study on clinical outcomes in patients with femoropopliteal lesions and subcritical or critical lower limb ischemia. Their study included 98 patients and 121 PTAs (21). The early mortality (30 days) reached $4.3 \%$. Kim et al. reported a mortality rate following the 12 -month period of follow-up among patients with femoropopliteal disease (TASC C and D lesions) and treated with PTA on 5.5\% (22). Whereas Kok et al. reported a mortality rate of $21 \%$ after a year-long follow-up in PAD patients treated for limb salvage. Mortality reached $50 \%$ after 5 years of follow-up (23). The study published previously by our team reported a 1 -year mortality rate at $5.8 \%$ among patients treated with retrograde vascular access with the mean follow-up at 13.9 [4] months (24). This mortality was lower compared to our study, where after 12 months, this equaled $6.8 \%$ in the total group, $6.1 \%$ in the non-COPD and $12.2 \%$ in the COPD group. One of the main causes in which one can see the difference in mortality is related to age. The average age in our previous publication was 5 years less. One of the few studies comparing the results of endovascular treatment of PAD from antegrade and retrograde access revealed comparable reintervention rates after the 5 -year follow-up period and was decreased among subjects with retrograde puncture; however, without statistical significance $(27.3 \%$ vs. $36 \%)$. Unfortunately, those studies did not deliver information on mortality rate (2). Another study assessing the effectiveness and clinical outcomes during the mean 17-month-long follow-up showed that the mortality rate in patients with critical limb ischemia and pedal vascular access was $23 \%$ during the mean follow-up period of 6 [4] months (25). In this case, an increased risk of mortality should be seen in a large percentage of patients with diabetes that was $76.9 \%$. A systematic review including above 1,500 patients state a 1 -year survival rate among subjects treated using subintimal recanalization dependent on culprit artery location or symptoms prior to angioplasty. The rate was between $65 \%$ and $78 \%$ among patients with critical limb ischemia and crural lesion and was between $86 \%$ and $100 \%$ in patients with mixed-disease as well as femoral lesions (26). We may list prothrombotic state connected with COPD, increased pro-inflammatory and oxidative stress markers as some of the most significant mechanisms accountable for worse clinical outcome following lower limb artery PTA in the follow-up $(27,28)$. The correlation between COPD and 
cardiovascular adverse events in the future among patients experiencing coronary artery disease has been presented on numerous occasions $(29,30)$. In this study, a great patient percentage having coronary heart disease in the COPD group seem to be of great relevance, which can be connected with the higher occurrence rate of heart failure as well as various types of cardiac arrhythmia that may lead to sudden cardiac death. However, we do not have data on the incidence of heart failure or the causes of deaths in the follow-up period, which limits inference in this field. One of various factors, for which a strong correlation with endovascular outcome during the follow-up period can be found, is kidney failure. Kidney failure was viewed as a predictor of higher death rate after 4-year followup among PAD patients subjected PTA. This was strictly associated with kidney-failure stage. The predicted 4-year mortality rate among patients with diagnosed kidney failure was $27 \%$, however, in the case of patients with different stages, these values were $46 \%$ (stage 2), $52 \%$ (stage 3 ), $72 \%$ (stage 4 ) and $78 \%$ (stage 5) (8). In the analyzed results of the present study, both the creatinine level and the percentage of patients with renal insufficiency was not significantly different concerning patients with or without COPD. Female gender was found to be associated with the increased death rate in selected subgroups of patients with cerebrovascular, coronary artery disease and black race. Those differences dissipated in octogenarians and patients with claudication (4). In the current study, the percentage of males was higher in the COPD group in comparison to the non-COPD. While the mortality rate was significantly higher in the COPD group. Thus, the increased rate of death was rather related to male than female gender. Also, diabetes is found to be an autonomous predictor of increased death rate among patients with PAD and critical limb ischemia treated with endovascular interventions (20). In the presented study, the percentage of patients with diabetes was higher in the non-COPD compared to COPD, and this was probably mostly owed to the higher percentage of females in this subgroup. However, in the current study, this factor seems to be not influential enough to modify the overall rate of mortality during follow-up.

Nevertheless, available publications have shown a number of factors related to the frequency of adverse events and vascular patency in the follow-up period. The culprit lesion length, a clinical state prior to angioplasty and the extent of atherosclerotic lesion distribution (TASC stage) can be found as some of the definite predictors of clinical outcome for PAD patients undergoing endovascular intervention treatment (21). This, at least in part, is reflected in our data, in which patients with significantly higher mortality from the COPD group had significantly higher rates of multi-segmental lesions expressed as TASC D stage or longer mean culprit lesion length. Also, other wellknown predictors of mortality during the follow-up period like diabetes, kidney failure or poor run off into the foot were found to predict graft failure in patients undergoing endovascular infra-inguinal revascularization (31). Recently published studies confirmed the relationship between COPD and smoking and clinical outcomes in patients with coronary artery diseases treated with PCI (32). Patients with COPD previously treated with PCI and smokers were at increased risk of in-stent thrombosis and restenosis. Additionally, COPD was found to be related to disseminated coronary atherosclerosis. More advanced and multi-segmental involvement of atherosclerosis found in patients with coronary artery disease and COPD was reflected in the current study, where TASC D lesions were significantly more frequently found in the COPD group as compared to the non-COPD. In the current study, concomitant COPD was not found to be a significant predictor of clinical outcomes other than mortality in patients with PAD treated with endovascular intervention from retrograde access. We noticed some variations regarding clinical outcome, nonetheless, they were not statistically significant. For example, re-PTA occurred more often in the non-COPD group, while myocardial infarction, amputation, and lower extremity bypass rate were more common among the COPD group when juxtaposed with non-COPD. A larger amount of re-PTAs for non-COPD patients may be the consequence of lower mortality and the associated possibility of such treatment.

\section{Limitations}

In this study, we may detect a number of limitations, one being the fact that we do not possess data on the etiology of deaths during the follow-up period and other concomitant diseases at baseline including heart failure or cardiac arrhythmias. In addition, we have no data on COPD, pneumonia or exacerbations of heart failure, which at this age, may be a potential cause of death for every hospitalization, apart from cardiological causes. There are also many other factors like sample size which may bring some bias to the present study. One of the most important is the coexistence of many comorbidities in the COPD group compared to patients without COPD at a much higher percentage, which 
in itself, may decide about increased mortality.

\section{Conclusions}

Patients experiencing COPD as well as peripheral arterial disease concerning the infra-inguinal lower limb arteries undergoing endovascular recanalization of chronic total occlusions from retrograde access are related to the increased rate of deaths during follow-up. The results obtained in the presented study confirm the relationships observed in other groups of patients with atherosclerosis undergoing percutaneous procedures. Thus, it can be concluded that the impact of CTO and chronic, often critical, ischemia of large muscle groups could modify the effect of particular coexisting comorbidities and long-term clinical outcomes. The presence of COPD is associated with higher mortality, which may be a consequence of more advanced comorbidities, and the less frequent occurrence of re-PTA with a natural selection of patients more burdened with concomitant diseases. Therefore, the most appropriate approach in this group of patients, aimed at reducing mortality in the follow-up period, is multidisciplinary control of comorbidities and risk factors for atherosclerosis.

\section{Acknowledgments}

Funding: None.

\section{Footnote}

Conflicts of Interest: The authors have no conflicts of interest to declare.

Ethical Statement: The authors are responsible for each and every part of the paper when guaranteeing that issues concerning the accurateness or reliability of any section of the article have been properly examined and determined. The protocol was in accordance with the 1964 Declaration of Helsinki, and all of the participants gave their informed and written consent to take part in the trial. Due to the fact that the data in the study were collected retrospectively, the consent of the Bioethics Committee was not required.

Open Access Statement: This is an Open Access article distributed in accordance with the Creative Commons Attribution-NonCommercial-NoDerivs 4.0 International License (CC BY-NC-ND 4.0), which permits the noncommercial replication and distribution of the article with the strict proviso that no changes or edits are made and the original work is properly cited (including links to both the formal publication through the relevant DOI and the license). See: https://creativecommons.org/licenses/by-nc-nd/4.0/.

\section{References}

1. Ruzsa Z, Wojtasik-Bakalarz J, Nyerges A, et al. LongTerm Follow-up After Retrograde Recanalization of Superficial Femoral Artery Chronic Total Occlusion. J Invasive Cardiol 2017;29:336-9.

2. Evans C, Peter N, Gibson M, et al. Five-year retrograde transpopliteal angioplasty results compared with antegrade angioplasty. Ann R Coll Surg Engl 2010;92:347-52.

3. Pasqualini L, Schillaci G, Pirro M, et al. Renal dysfunction predicts long-term mortality in patients with lower extremity arterial disease. J Intern Med 2007;262:668-77.

4. Vouyouka AG, Egorova NN, Salloum A, et al. Lessons learned from the analysis of gender effect on risk factors and procedural outcomes of lower extremity arterial disease. J Vasc Surg 2010;52:1196-202.

5. Jackson EA, Munir K, Schreiber T, et al. Impact of sex on morbidity and mortality rates after lower extremity interventions for peripheral arterial disease: observations from the Blue Cross Blue Shield of Michigan Cardiovascular Consortium. J Am Coll Cardiol 2014;63:2525-30.

6. Cherr GS, Wang J, Zimmerman PM, et al. Depression is associated with worse patency and recurrent leg symptoms after lower extremity revascularization. J Vasc Surg 2007;45:744-50.

7. Stone PA, Schlarb H, Campbell JE, et al. C-reactive protein and brain natriuretic peptide as predictors of adverse events after lower extremity endovascular revascularization. J Vasc Surg 2014;60:652-60.

8. Lüders F, Bunzemeier H, Engelbertz C, et al. CKD and Acute and Long-Term Outcome of Patients with Peripheral Artery Disease and Critical Limb Ischemia. Clin J Am Soc Nephrol 2016;11:216-22.

9. Desormais I, Aboyans V, Bura A, et al. Anemia, an independent predictive factor for amputation and mortality in patients hospitalized for peripheral artery disease. Eur J Vasc Endovasc Surg 2014;48:202-7.

10. Vogelmeier CF, Criner GJ, Martinez FJ, et al. Global Strategy for the Diagnosis, Man-agement, and Prevention of Chronic Obstructive Lung Disease 2017 Report: GOLD Ex-ecutive Summary. Eur Respir J 2017;49. doi: 10.1183/13993003.00214-2017. 
11. Huang X, Redfors B, Chen S, et al. Impact of chronic obstructive pulmonary disease on prognosis after percutaneous coronary intervention and bypass surgery for left main coronary artery disease: an analysis from the EXCEL trial. Eur J Cardiothorac Surg 2019;5 5:1144-51.

12. Enriquez JR, Parikh SV, Selzer F, et al. Increased adverse events after percutaneous coronary intervention in patients with COPD: insights from the National Heart, Lung, and Blood Institute dynamic registry. Chest 2011;140:604-10.

13. Habib N, Mahmoodi BK, Suttorp MJ, et al. Long-term results of carotid stenting and risk factors in patients with severe carotid artery stenosis undergoing subsequent cardiac surgery. Catheter Cardiovasc Interv 2019;93:E134-9.

14. Terzikhan N, Lahousse L, Verhamme KMC, et al. COPD is associated with an increased risk of peripheral artery disease and mortality. ERJ Open Res 2018;4. doi: 10.1183/23120541.00086-2018.

15. Rutherford RB, Baker JD, Ernst C et al. Recommended standards for reports dealing with lower extremity ischemia: revised version. J Vasc Surg 1997;26:517-38.

16. Fontaine R, Kim M, Kieny R. Surgical treatment of peripheral circulation disorders. Helv Chir Acta 1954;21:499-533.

17. Wagner FW Jr. The diabetic foot. Orthopedics 1987;10:163-72.

18. Norgren L, Hiatt WR, Dormandy JA, et al. Inter-Society Consensus for the Management of Peripheral Arterial Disease (TASC II). Eur J Vasc Endovasc Surg 2007;33 Suppl 1:S1-75.

19. Tønnesen KH, Sager P, Karle A, et al. Percutaneous transluminal angioplasty of the su-perficial femoral artery by retrograde catheterization via the popliteal artery. Cardiovasc Intervent Radiol 1988;11:127-31.

20. Bertelè V, Roncaglioni MC, Pangrazzi J, et al. Clinical outcome and its predictors in 1560 patients with critical leg ischaemia. Chronic Critical Leg Ischaemia Group. Eur J Vasc Endovasc Surg 1999;18:401-10.

21. Löfberg AM, Karacagil S, Ljungman C, et al. Percutaneous transluminal angioplasty of the femoropopliteal arteries in limbs with chronic critical lower limb ischemia. J Vasc Surg 2001;34:114-21.

22. Kim SJ, Kim W, Kim JB, et al. Determinants of procedural success and patency following subintimal angioplasty in patients with TASCC and Dfemoropopliteal arterial disease. Circ J 2010;74:1959-64.

23. Kok HK, Asadi H, Sheehan M, et al. Outcomes of infrapopliteal angioplasty for limb salvage based on the updated TASC II classification. Diagn Interv Radiol 2017;23:360-4.

24. Wojtasik-Bakalarz J, Arif S, Chyrchel M, et al. Twelve months follow-up after retrograde recanalization of superficial femoral artery chronic total occlusion. Postepy Kardiol Interwencyjnej 2017;13:47-52.

25. Bazan HA, Le L, Donovan M, et al. Retrograde pedal access for patients with critical limb ischemia. J Vasc Surg 2014;60:375-81.

26. Met R, Van Lienden KP, Koelemay MJ, et al. Subintimal angioplasty for peripheral arterial occlusive disease: a systematic review. Cardiovasc Intervent Radiol 2008;31:687-97.

27. Mejza F, Lamprecht B, Niżankowska-Mogilnicka E, et al. Arterial and venous throm-boembolism in chronic obstructive pulmonary disease: from pathogenic mechanisms to prevention and treatment. Pneumonol Alergol Pol 2015;83:485-94.

28. Maclay JD, McAllister DA, Johnston S, et al. Increased platelet activation in patients with stable and acute exacerbation of COPD. Thorax 2011;66:769-74.

29. Christie DJ, Kottke-Marchant K, Gorman RT. Hypersensitivity of platelets to adenosine diphosphate in patients with stable cardiovascular disease predicts major adverse events despite antiplatelet therapy. Platelets 2008;19:104-10.

30. Gianetti J, Parri MS, Sbrana S, et al. Platelet activation predicts recurrent ischemic events after percutaneous coronary angioplasty: a 6 months prospective study. Thromb Res 2006;118:487-93.

31. Black JH 3rd, LaMuraglia GM, Kwolek CJ, et al. Contemporary results of angioplas-ty-based infrainguinal percutaneous interventions. J Vasc Surg2005;42:932-9.

32. Januszek R, Siudak Z, Dziewierz A, et al. Chronic obstructive pulmonary disease affects the angiographic presentation and outcomes of patients with coronary artery disease treated with percutaneous coronary interventions. Pol Arch Intern Med 2018;128:24-34.

Cite this article as: Ruzsa Z, Januszek R, Óriás V, Chyrchel M, Wojtasik-Bakalarz J, Bartuś J, Arif S, Kleczyński P, Tokarek T, Nyerges A, Stanek A, Dudek D, Bartuś S. Mortality and chronic obstructive pulmonary disease in patients treated with endovascular revascularization of the infra-inguinal lower limb arteries from retrograde access. Ann Transl Med 2020;8(5):206. doi: 10.21037/atm.2020.01.57 